\title{
Effects of Aging Treatment on the Bending Strength in $\mathrm{AZ91D} / \mathrm{Al}_{18} \mathrm{~B}_{4} \mathrm{O}_{33 \mathrm{w}}$ Composite
}

\author{
W. G. Wang ${ }^{1}$, W. L. Li ${ }^{2}$, K. C. Chang ${ }^{1}$, K. Matsugi ${ }^{1}$ and G. Sasaki ${ }^{1}$ \\ ${ }^{1}$ Department of Mechanical System Engineering, Graduate School of Engineering, Hiroshima University, \\ Higashi-Hiroshima 739-8527, Japan \\ ${ }^{2}$ Department of Mechanical Engineering, Tokushima University, Tokushima 770-8506, Japan
}

Aluminum borate whisker $\left(\mathrm{Al}_{18} \mathrm{~B}_{4} \mathrm{O}_{33 \mathrm{w}}\right.$, denoted by $\left.\mathrm{ABO}_{\mathrm{w}}\right)$ reinforced $\mathrm{AZ91D}(\mathrm{Mg}-\mathrm{Al}-\mathrm{Zn}$ ) magnesium alloy composites were prepared by squeeze casting. The composite was solution-treated at $683 \mathrm{~K}$ for $345.6 \mathrm{ks}$ in argon atmosphere and then water-quenched. Aging treatment was carried out at $443 \mathrm{~K}$ in oil-bath. While the composite was cooled from the solution temperature of $683 \mathrm{~K}$ to room temperature, large thermal residual stress (TRS) was formed due to the mismatch of thermal expansion coefficient between $\mathrm{ABO}_{\mathrm{w}}$ and AZ91D matrix. The TRS of AZ91D matrix in as-quenched $\mathrm{AZ91D} / \mathrm{ABO}_{\mathrm{w}}$ composite was measured with X-ray diffraction (XRD) and it was $103 \mathrm{MPa}$. After aging for $115.2 \mathrm{ks}$, the TRS relaxed and decreased to $45 \mathrm{MPa}$. Owing to the formation of precipitates, the bending strength of peak-aged composite (aged for $115.2 \mathrm{ks}$ ) was enhanced. Nevertheless, when the composite was aged for $345.6 \mathrm{ks}$, the bending strength decreased greatly. Even the bending strength of over-aged composite was lower than that of as-quenched composite. It is attribute to the coarsening of continuous precipitate within composite matrix close to whiskers. [doi:10.2320/matertrans.MER2007302]

(Received December 3, 2007; Accepted January 21, 2008; Published March 12, 2008)

Keywords: AZ91D magnesium alloy, aluminum borate whisker, composite, bending strength, aging, thermal residual stress.

\section{Introduction}

In recent years, there has an increasing interest in researching and developing discontinuously reinforced magnesium matrix composites for applications in aerospace, automobile and transport industries, due to their low density, high specific strength and specific stiffness, high wear resistance and low coefficient of thermal expansion than the conventional magnesium alloy.

Many investigations were carried out on the fabrication and mechanical properties of magnesium alloy matrix composites. The previous researches indicate that the mechanical properties of these composites depend on variety of factors, such as the size, shape and volume fraction of reinforcement; ${ }^{1-3)}$ fabrication method of the composites; $;$,5) secondary processing $;{ }^{6)}$ the internal residual stress ${ }^{7,8)}$ and the nature of matrix-reinforcement interfaces ${ }^{9,10)}$ and so on.

Moreover, many discontinuously reinforced composites are based on age-hardenable light alloys. Unlike continuously reinforced composites, of which the properties are mainly influenced by fibers, the properties of the discontinuously reinforced composites seem to be influenced more greatly by matrix properties. As well known, Mg-Al-based alloys are age-hardenable. ${ }^{1-14)}$ So it is possible that aging treatment can change greatly the mechanical properties of these composites. Although many investigations on precipitation behaviors in magnesium alloy matrix composites have been carried out, ${ }^{15-18)}$ there is little information available about the effects of aging treatment on mechanical properties of magnesium alloy matrix composites.

The aim of this study is to clarify the effect of aging treatment on the bending strength of $\mathrm{Mg}$-Al-based alloy matrix composites from the viewpoints of microstructures development and internal residual stress, and provide information for designing the properties of composites.

\section{Experimental Procedure}

Commercial AZ91D magnesium alloy reinforced with $30 \%$-volume fraction of $\mathrm{ABO}_{\mathrm{w}}$ (ALBOREX M12, produced by Shikoku Chemicals Company) was fabricated by squeeze casting. The sizes of whiskers were $0.5 \sim 1.0 \mu \mathrm{m}$ in diameter and $10 \sim 30 \mu \mathrm{m}$ in length, and the whisker surfaces is smooth in atomic scale. The matrix was AZ91D magnesium alloy in common usage and the chemical composition of its alloy was Mg-9.1 mass\%Al-0.7 mass\%Zn-0.3 mass\%Mn.

$\mathrm{AZ91D} / \mathrm{ABO}_{\mathrm{w}}$ composite was solution-treated at $683 \mathrm{~K}$ for 4 days in argon atmosphere and then water-quenched. Furthermore, the aging treatment was carried out $443 \mathrm{~K}$ in oil bath. The AZ91D monolithic alloy was prepared in the similar way for the sake of comparing.

The rectangular specimens were prepared for three points bending in size of $3 \times 4 \times 30 \mathrm{~mm}$. The specimens were polished to a mirror finish on one face and the edges of the specimens were beveled $45^{\circ}$ to reduce the likelihood of edge initiated failures. Bending test was carried out at a rate of $0.5 \mathrm{~mm} / \mathrm{min}$. Under same condition, the experiments were carried out at least ten times. And maximum and minimum were neglected. The bending strengths of both AZ91D alloy and composite were measured.

The TRS of matrix in $\mathrm{AZ91D} / \mathrm{ABO}_{\mathrm{w}}$ composite was estimated by XRD method. For the sake of minimizing the residual stress caused by machine milling, the specimens were etched with $1 \%$ nitric acid and $99 \%$ ethanol for 10 seconds, and then rinsed with ethanol for avoiding oxidation.

Moreover, the microstructures of composite were observed with scanning electron microscopy (SEM) and transmission electron microscopy (TEM). The samples for TEM investigation were prepared. At first, disks of $3 \mathrm{~mm}$ in diameter, $200 \mu \mathrm{m}$ in thickness were punched from the composite foils for subsequent mechanical polishing and argon ion milling. 

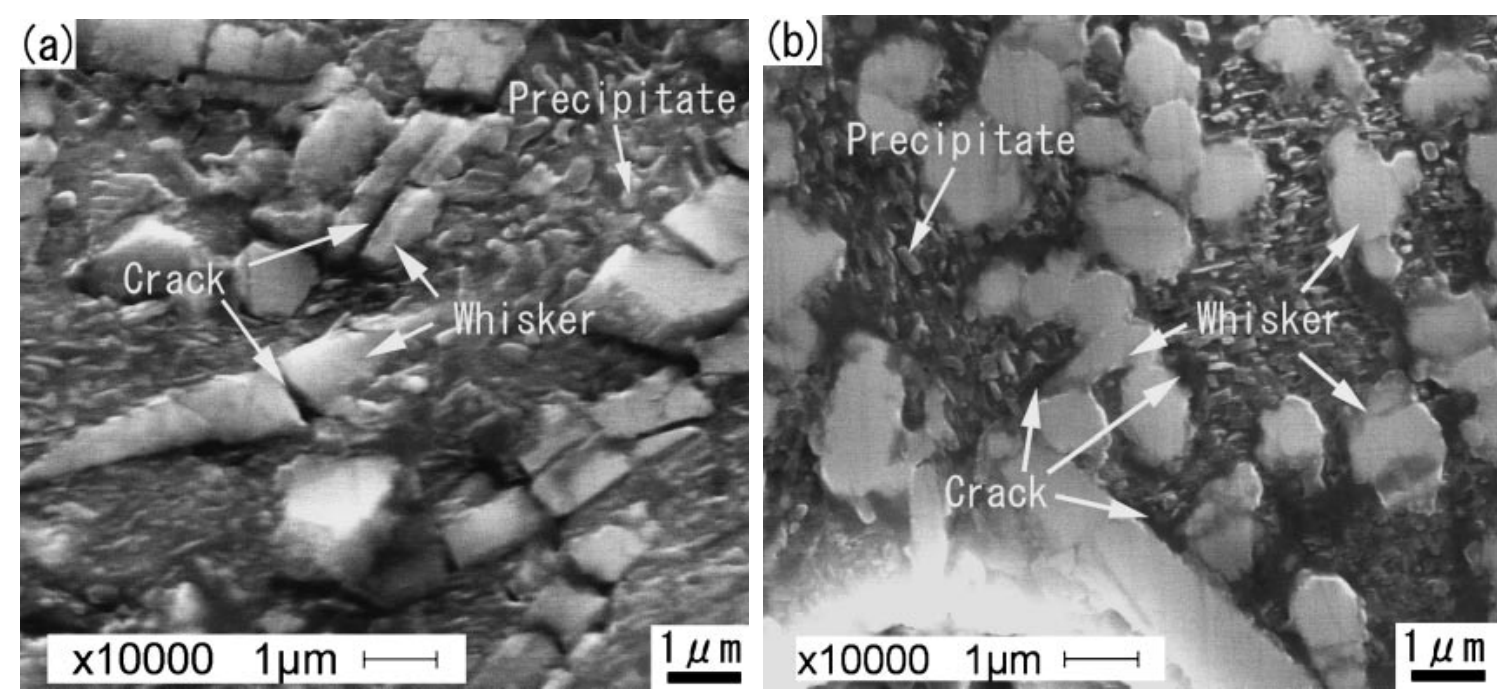

Fig. 1 Profile images of the composite bending samples observed with SEM. (a) peak-aged (at $443 \mathrm{~K}$ for $115.2 \mathrm{ks}$ ) and (b) over-aged (at $443 \mathrm{~K}$ for $345.6 \mathrm{ks}$ ), respectively.

Table 1 The bending strength of AZ91D alloy and AZ91D/ABO $\mathrm{w}_{\mathrm{w}}$ composite, and thermal residual stress (TRS) of composite matrix that they were aged at $443 \mathrm{~K}$.

\begin{tabular}{|c|c|c|c|c|c|c|}
\hline \multirow[b]{2}{*}{$\begin{array}{l}\text { Aging } \\
\text { time }\end{array}$} & \multicolumn{3}{|c|}{ AZ91D alloy } & \multicolumn{3}{|c|}{ AZ91D/ABO ${ }_{w}$ composite } \\
\hline & $7.2 \mathrm{ks}$ & $\begin{array}{c}216 \mathrm{ks} \\
\text { (peak-aged) }\end{array}$ & $\begin{array}{c}648 \mathrm{ks} \\
\text { (over-aged) }\end{array}$ & $0 \mathrm{ks}$ & $\begin{array}{c}115.2 \mathrm{ks} \\
\text { (peak-aged) }\end{array}$ & $\begin{array}{c}345.6 \mathrm{ks} \\
\text { (over-aged) }\end{array}$ \\
\hline $\begin{array}{l}\text { Bending } \\
\text { strength }\end{array}$ & $352 \mathrm{MPa}$ & $381 \mathrm{MPa}$ & $357 \mathrm{MPa}$ & $570 \mathrm{MPa}$ & $591 \mathrm{MPa}$ & $536 \mathrm{MPa}$ \\
\hline TRS & - & - & - & $103 \mathrm{MPa}$ & $45 \mathrm{MPa}$ & $44 \mathrm{MPa}$ \\
\hline
\end{tabular}

In order to retain the actual estates of materials, these experiments were kept at room temperature. TEM observations were carried out with JEOL JEM-2010 microscope.

\section{Results and Discussion}

According to previous study, ${ }^{19)}$ it needs $216 \mathrm{ks}$ and $115.2 \mathrm{ks}$ aging that the hardness of AZ91D alloy and $\mathrm{AZ91D} / \mathrm{ABO}_{\mathrm{w}}$ composite get to peak values, respectively. Due to the good ductility of as-quenched AZ91D alloy, the bending strength of as-quenched AZ91D alloy cannot be measured. After aged for $7.2 \mathrm{ks}$, the bending strength of AZ91D alloy is measured. Table 1 shows the bending strengths of AZ91D alloy and AZ91D/ABO $\mathrm{A}_{\mathrm{w}}$ composite aged at $443 \mathrm{~K}$. When the hardness gets to peak value, the bending strength of AZ91D alloy and AZ91D/ABO posite are enhanced respectively. With increasing of aging time, the bending strength of AZ91D alloy and AZ91D/ $\mathrm{ABO}_{\mathrm{w}}$ composite decrease. After aged for $345.6 \mathrm{ks}$, the bending strength of over-aged composite declines greatly. Even bending strength of over-aged composite is lower than that of as-quenched composite. It is assumed that the fracture mechanism in $\mathrm{AZ91D} / \mathrm{ABO}_{\mathrm{w}}$ composite is different from that in AZ91D alloy.

Mechanical properties of materials are relevant to not only microstructure but also internal residual stress. ${ }^{7,8)}$ As well known, TRS is formed due to the mismatch of the coefficients of thermal expansion (CTE) between reinforcement and matrix in metal matrix composite. While the $\mathrm{AZ91D} / \mathrm{ABO}_{\mathrm{w}}$ composite is cooled from solution temperature to room temperature, large TRS is formed in as-quenched AZ91D/ $\mathrm{ABO}_{\mathrm{w}}$ composite. The TRS of AZ91D matrix in as-quenched $\mathrm{AZ91D} / \mathrm{ABO}_{\mathrm{w}}$ composite is $103 \mathrm{MPa}$ measured with XRD, as shown in Table 1 . With the increasing of aging time, the TRS relaxes. The TRS of peak-aged composite matrix decreases to $45 \mathrm{Mpa}$. After getting to peak-aged, the TRS changes scarcely. It is thought that the TRS of $45 \mathrm{MPa}$ is formed when the composite is cooled from aging temperature $(443 \mathrm{~K})$ to room temperature. It indicates that the declining of composite bending strength is not caused by the change of TRS.

In order to clarify the fracture mechanism of composite, the fracture surface profiles of bending specimens are observed with SEM. Figure 1(a) shows that most of whiskers are fractured in peak-aged specimen. The interface between reinforcement and matrix has sufficient strength to transfer load. And it is indicated that whiskers bear large stress when the composite is fractured. Moreover, in over-aged composite, many cracks are found at the interfaces between matrix and $\mathrm{ABO}_{\mathrm{w}}$ or the matrix close to whiskers, as shown in Fig. 1(b). The damage degree of whiskers in over-aged composite is slighter than that in peak-aged composite. In addition, cracks can be found in Fig. 1(b), which suggests that the fracture of interface in over-aged composite may be important to affect the fracture mechanism of over-aged composite. 

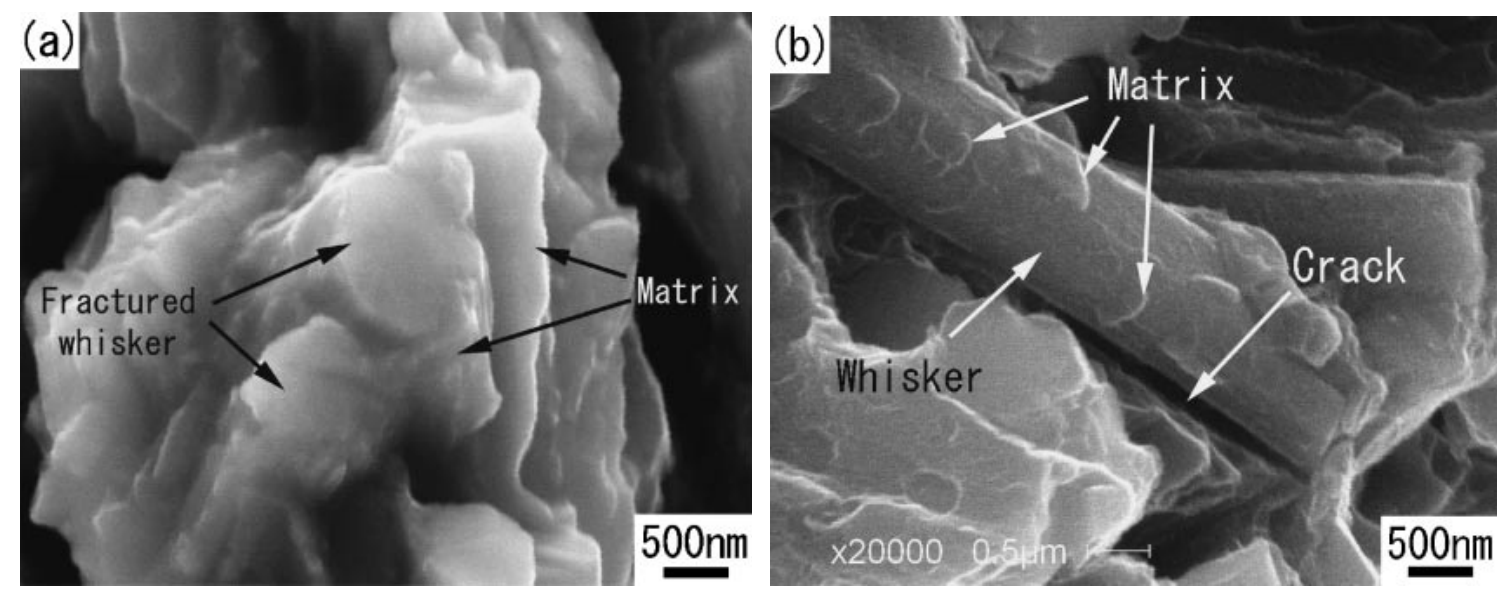

Fig. 2 SEM fractographs of (a) peak-aged (aged at $443 \mathrm{~K}$ for $115.2 \mathrm{ks}$ ) and (b) over-aged (aged at $443 \mathrm{~K} \mathrm{for} 345.6 \mathrm{ks}$ ) AZ91D/ABO composite, respectively.
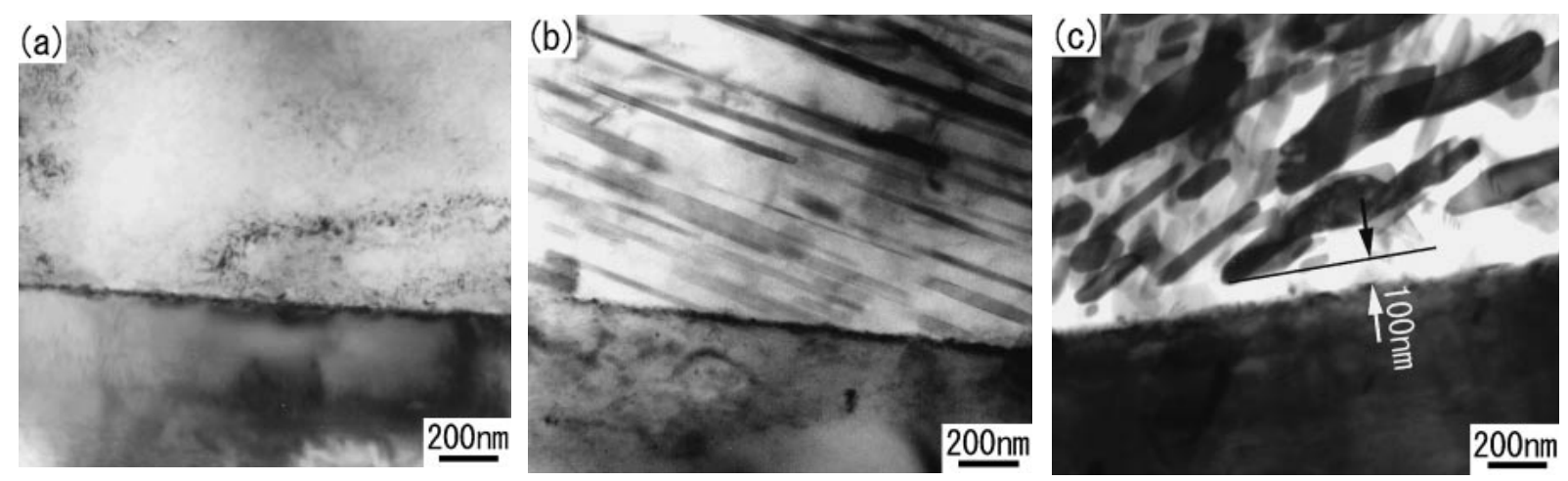

Fig. 3 TEM images of microstructures nearby whiskers in AZ91D/ABO ${ }_{w}$ composites that is (a) As-quenched, (b) Peak-aged (at $443 \mathrm{~K}$ for $115.2 \mathrm{ks}$ ) and (c) Over-aged (at $443 \mathrm{~K}$ for $345.6 \mathrm{ks}$ ).

Figure 2(a) and (b) are SEM fractographs of the specimens aged at $443 \mathrm{~K}$ for $115.2 \mathrm{ks}$ (peak-aged) and $345.6 \mathrm{ks}$ (overaged) respectively. Figure 2(a) shows that many whiskers are fractured when the specimen is bended, and some matrix is remained around whiskers. It indicates that adequate interfacial bonding is achieved between $\mathrm{ABO}_{\mathrm{w}}$ and matrix, and $\mathrm{ABO}_{\mathrm{w}}$ bears large stress when the material is fractured. For over-aged composite, fractures occur mainly at the matrix close to whiskers and some ripple-like matrix is remained on the surfaces of whiskers, as shown in Fig. 2(b). It indicates that the microstructures of the matrix close to whiskers are changed greatly after getting to peak-aged, and the cracks propagate easily near by interface. When the composite is fractured, high strength advantage of $\mathrm{ABO}_{\mathrm{w}}$ is not brought into play, and the composite fails under lower stress. As a result, the bending strength of over-aged composite declines greatly.

As well known, interfacial reaction layer plays an important role in determining the mechanical properties of metal/ ceramics composites. $\left.{ }^{9}, 10\right)$ So it is necessary to discuss the effects of interfacial reaction layer on fracture behaviors of composite. According to previous investigation, ${ }^{20)}$ the whiskers are wrapped completely with $\mathrm{MgO}$ interfacial reaction layer after solution treatment at $693 \mathrm{~K}$ for $172.8 \mathrm{ks}$. The interfacial reaction layer is consisted of tiny $\mathrm{MgO}$ particles and these $\mathrm{MgO}$ particles play a good barrier to keep out of interfacial reaction between matrix and whisker. When the solution treatment time gets to $345.6 \mathrm{ks}$, the microstructure of interfacial reaction layer surfaces does not change. In present study, the microstructures of interfacial reaction layer do not change in the process of aging treatment. In other words, the bonding strength of interface between matrix and whisker does not change under aging treatment.

Generally, there are two aspects, affecting the fracture mechanism of composite, related with reinforcement. First, cracks initiate at the reinforcements, resulting in the failure of composite. Second, fractures initiate at the debonded matrix/ reinforcement interfaces or the matrix close to reinforcements. In present investigation, adequate interfacial bonding is achieved between the $\mathrm{ABO}_{\mathrm{w}}$ and the AZ91D matrix, as shown in Fig. 2(a). And no evidence is found that the nature of interfacial bonding is altered under aging treatment in $\mathrm{AZ91D} / \mathrm{ABO}_{\mathrm{w}}$ composite. Figure 2(b) shows that fractures occur at the matrix close to whiskers and a thin layer of matrix is remained at the surface of whisker. It is thought that fractures occur at the matrix close to whiskers. It assumes that the change of fracture characteristic is caused by change of microstructure in the matrix close to whiskers, which results in the strength declining of the composite.

In order to observe the development of microstructure in composite matrix close to whisker, TEM observations are carried out. Figure 3(a), (b) and (c) reveal the microstructures 
in as-quenched, peak-aged and over-aged composite. After solution treatment, homogeneous $\alpha$-phase matrix and thin interfacial reaction layer is formed in the composite, as shown in Fig. 3(a). For peak-aged composite, a great number of continuous precipitates form in composite matrix, and these continuous precipitates extend to the surfaces of whiskers, as shown in Fig. 3(b). According to previous investigations, the formation of continuous precipitates can enhance the mechanical properties of $\mathrm{Mg}$-Al-based alloy. ${ }^{21-23)}$ As a result, the bending strength of $\mathrm{Mg}$-Al-based alloy matrix composite is enhanced. With increasing aging time, the coarsening of precipitates is observed in composite matrix, as shown in Fig. 3(c). The continuous precipitates become more irregular. After getting to peak-aged, the faceted edges of the laths-shaped and plate-shaped precipitates are becoming rounded. In the matrix close to whiskers, there forms a thin precipitate free layer of $\alpha$-phase in thickness of $100 \mathrm{~nm}$. Similar observation on coarsening of continuous precipitates in $\mathrm{Mg}$-Al-based alloy has been found. Celotto et al. ${ }^{11)}$ have investigated the precipitates behaviors in $\mathrm{Mg}-9$ mass\% $\mathrm{Al}-1$ mass\%Zn alloy aged from $343 \mathrm{~K}$ to $573 \mathrm{~K}$. They found that maximum hardness is reached when the lath-shaped continuous precipitates grow to their maximum length. After getting to peak-aged, the faceted edges of the laths-shaped precipitates are becoming rounded. The width of continuous precipitates increase and the length of continuous precipitates declines.

When $\mathrm{AZ91D} / \mathrm{ABO}_{\mathrm{w}}$ was deformed, stress concentration will occur at the matrix nearby whiskers and the inner of whiskers. In peak-aged composite, precipitates distribute uniformly in the matrix, and fractures occur mainly at the whiskers resulting in the failure of composite. After getting to peak-aged, there forms a precipitate free layer of $\alpha$-phase matrix nearby whiskers due to the coarsening of continuous precipitates. This precipitate free layer of $\alpha$-phase matrix close to whiskers has lower aluminum concentration since aluminum elements of matrix are depleted by precipitations under aging treatment. Therefore the strength of this layer of matrix in over-aged composite is lower than that of supersaturated AZ91D magnesium alloy matrix in as-quenched composite. As a result, the bending strength of over-aged composite is lower than that of as-quenched composite.

Moreover, the effects of thermal residual stress on tensile strength in $\mathrm{Al} / \mathrm{ABO}_{\mathrm{w}}$ composite have been studied. ${ }^{8)}$ The relaxation of TRS will enhance the $\sigma_{0.05}, \sigma_{0.02}$ (yield strength) and $\sigma_{b}$ (ultimate tensile strength) of $\mathrm{Al} / \mathrm{ABO}_{\mathrm{w}}$ composite. The effects of TRS on mechanical properties in AZ91D/ $\mathrm{ABO}_{\mathrm{w}}$ and $\mathrm{Al} / \mathrm{ABO}_{\mathrm{w}}$ composites are similar. Relaxation of TRS is propitious to develop the optimum properties of the composites. Although TRS has been relaxed, the bending strength of over-aged $\mathrm{AZ} 91 \mathrm{D} / \mathrm{ABO}_{\mathrm{w}}$ composites is lower than that of as-quenched $\mathrm{AZ} 91 \mathrm{D} / \mathrm{ABO}_{\mathrm{w}}$ composite. This validates further above conclusion that the bending strength declining of over-aged composites is attributed to the lower strength of precipitate free $\alpha$-phase matrix nearby whiskers. Through these investigations, it is seemly that the bending strength of AZ91D/ABOw composite is relative to the mechanical properties of the matrix close to whiskers.

\section{Conclusions}

While the composite is cooled from solution treatment temperature to room temperature, the large TRS is formed due to the mismatch of thermal expansion coefficient between $\mathrm{ABO}_{\mathrm{w}}$ and AZ91D matrix. The TRS of AZ91D matrix in as-quenched AZ91D/ABO ${ }_{\mathrm{w}}$ composite is $103 \mathrm{MPa}$. After aged for $115.2 \mathrm{ks}$, the TRS relaxes and decreases to $45 \mathrm{MPa}$. Aging treatment can relax TRS of AZ91D/ABO composite effectively.

Moreover, with increasing of aging time, the bending strength of composite increases initially. Nevertheless, after getting to the peak aging, the bending strength of composite decreases greatly. Even the bending strength of over-aged composite is lower than that of as-quenched composite. It is attributed to the strength deterioration of the matrix nearby whiskers. In over-aged composite, there forms a precipitate free layer of $\alpha$-phase matrix in thickness of $100 \mathrm{~nm}$ close to whiskers due to the coarsening of continuous precipitates. Fractures initiate at this $\alpha$-phase region having lower strength nearby whiskers, resulting in the great declining of composite bending strength.

\section{REFERENCES}

1) L. C. Davis, C. Andres and J. E. Allison: Mater. Sci. Eng. A249 (1998) 40-45.

2) B. W. Chua, L. Lu and M. O. Lai: Compo. Struct. 47 (1999) 595-601.

3) H. Lianxi and W. Erde: Mater. Sci. Eng. A278 (2000) 267-271.

4) H. Y. Wang, Q. C. Jiang, Y. Wang, B. X. Ma and F. Zhao: Mater. Lett. 58 (2004) 3509-3513.

5) S. K. Thakur and B. K. Dhindaw: Wear 247 (2001) 191-201.

6) G. Sasaki, M. Yoshida, N. Fuyama and T. Fujii: J. Mater. Proce. Tech. 130-131 (2002) 151-155.

7) Y. W. Bao, C. C. Liu and J. L. Huang: Mater. Sci. Eng. A434 (2006) 250-258.

8) W. D. Fei, M. Hu and C. K. Yao: Mater. Sci. Eng. A356 (2003) 17-22.

9) W. G. Chu, W. D. Fei, W. Yang and C. K. Yao: Mater. Chem. Phy. 68 (2001) 56-61.

10) J. Pan, A. Okamoto, S. P. Lee, G. Sasaki, M. Yoshida and H. Fukunaga: J. Japan Inst. 65 (2001) 199-206.

11) S. Celotto: Acta Mater. 48 (2000) 1775-1787.

12) A. F. Crawley: Acta Metall. 22 (1974) 557-562.

13) A. F. Crawley and B. Lagowski: Metall. Trans. 5 (1974) 949-951.

14) S. Celotto and T. J. Bastow: Acta Mater. 49 (2001) 41-51.

15) C. Badini, F. Marino, M. Montorsi and X. B. Guo: Mater. Sci. Eng. A157 (1992) 53-61.

16) M. Y. Zheng, K. Wu, S. Kamado and Y. Kojima: Mater. Sci. Eng. A348 (2003) 67-75.

17) Y. Cai, G. J. Shen and H. Q. Su: Scr. Mater. 37 (1997) 737-742.

18) S. Ikeno, K. Matsuda, S. Rengakuji and Y. Uetani: J. Mater. Sci. 36 (2001) 1921-1929.

19) W. G. Wang, K. Matsugi, O. Yanagisawa and G. Sasaki: The 10th JSME/ASME Int. Conf. on Mater. and Proc. (The Japan Soc. Mechan. Eng. and American Soc. Mechan. Eng., 2002) Vol. 2, 352-356.

20) W. G. Wang, K. Matsugi, H. Fukushima and G. Sasaki: Mater. Tran. 48 (2007) 1948-1955.

21) C. H. Caceres, C. J. Davidson, J. R. Griffiths and C. L. Newton: Mater. Sci. Eng. A325 (2002) 344-355.

22) T. Sumitomo, C. H. Caceres and M. Veidt: J. Light Metals 2 (2002) 4956.

23) D. Duly, J. P. Simon and Y. Brechet: Acta Metall. Mater. 43 (1995) 101-106. 